\title{
The inspiration of traditional folk house to the design of new rural residence
}

\author{
Hu Huang ${ }^{1,}$ a * \\ 1 Guangdong Vocational Institute of Science and Technology,Zhuhai, China. \\ ahuangh98@163.com
}

\begin{abstract}
Keywords:Traditional residence;New rural residence;Design
Abstract. Seek inspiration from the traditional houses, it is a way of thinking the author of the new rural housing design. This paper makes a deep analysis on the architectural features of the traditional houses, and discusses how to use and inherit the traditional residential space design concept in the design of new rural residential areas.
\end{abstract}

\section{Introduction}

Architecture as a medium to carry the culture, but also to the culture can be inherited. The traditional folk house is an important type of building in China, its production and development is the result of the comprehensive factors of social economy, historical culture and natural conditions, is the wisdom of the Chinese nation and sweat crystallization. Traditional houses not only simple and practical, strong adaptability, flexible construction, rich national style and local characteristics, but also has a unique historical and cultural and artistic value.

While traditional dwellings compared with many public buildings and landmarks, and its design is undoubtedly the plain and ordinary, but it is the people's daily lives, and bear with too much, too deep extension and content, there are many worthy study and explore issues. As a cultural heritage building traditional houses in a wide range of large, scattered in various regions of the country, has experienced vicissitudes of life, it carries a lot of historical information, waiting for us to recite. Now, the domestic research on traditional houses have been extensive and deepening how to inherit and carry forward the excellent traditional culture has become one of the core topics of research. Such hearts often confused: how should recognize past designer? How to inherit and carry forward the tradition be? In this paper, the author in recent years in terms of housing design experiences, to explore traditional houses Cognition and modern residential design inspiration, in order to start a discussion.

\section{Analysis of architectural features traditional house}

Traditional houses refers to a rustic, unofficial construction, civil geographical features, down from one generation to inherit the building type, building type living mainly in the "No architect designed building." Chinese traditional style houses rich and long history. From residential location, spatial layout and composition features and single building structure, space and materials and other aspects of traditional houses all reflect the local conditions and in harmony with nature, with respect to the structure housing, the Mountain, and the aptitude of the construction of architectural thought . Whether it is deep heavy northern residential or residential areas south of the beautiful and easy, are full of poetic rhythm, mood painting, ubiquitous expression "Heaven, people-oriented" cultural identity thinking.

Chinese traditional houses and diverse forms, from the hemispherical dome, hierarchical courtyard (Fig.1), the coarse ore quaint, dignified and strong Tibetan Blockhouse (Fig.2), to the yard, exquisite light on stilts (Fig.3), white walls and gray tiles, quiet and elegant Jiangnan (Fig.4). Houses under certain special historical conditions and the environment, they tend to have a certain degree of

particularity in the functional form. The most typical image of Fujian Hakka Earth Building(Fig.5), inhabited by a family and as a unit, defensive performance is outstanding; Xinjiang again as 
residential areas, due to the strong local sunshine during the day, so the thermal insulation of residential buildings with higher requirements;Cave Loess Plateau, the Yangtze River Delta "pillow

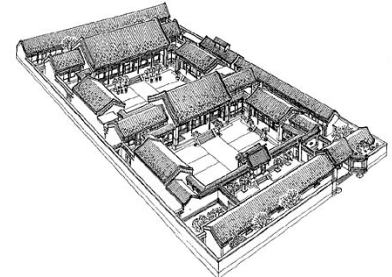

Fig.1

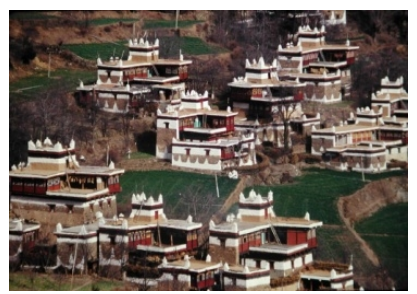

Fig.2

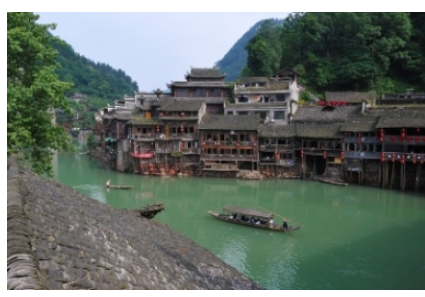

Fig.3

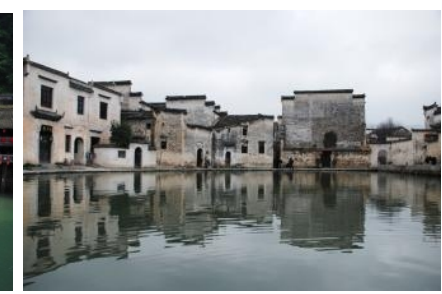

Fig.4

flow", Guizhou Shiban Fang, etc., are also integrated into the environment, in harmony with nature, according to local conditions, the formation of a highly local characteristics of the residential system.

Chinese courtyard-style houses is the most common type of residence, such as "YiKeYin" Houses in Yunnan and Patio residential areas in Huizhou. The courtyard to the sun and rain, sun essence, gas ventilation. The courtyard is not only the living center, but also the best place to cooperate with nature, Therefore, in many parts of the houses in the courtyard and introduce the natural scenery, still indoor using various plants, bonsai, bottle in, stone cleverly the artificial and natural combination in the moderate range, so that their source in nature is higher than the natural. Will the scenery of nature to be refined, in multum in parvo, nearly through far, reached the various scenic spots, right close mountains natural feeling. The traditional Chinese courtyard layout contains a large number of the construction entity modeling elements, such as back seat room, Chuihua doors, screen wall, principal rooms, rooms, Chao Shou veranda, which reflects the traditional architectural style. The traditional courtyard mode, the wall of the building with a deep impression of the deep penetration into people's spirit, is the "home" complex. Chinese traditional culture and the traditional style of Chinese traditional residence are mutually influenced, China's profound traditional culture has contributed to the traditional Chinese architectural form, the courtyard building in the structural style, artistic conception and other aspects of traditional culture also reflects the spiritual connotation of traditional culture, This shows that the Chinese culture as "hospital" culture is the basis to follow, we want to create a suitable living room home will have to understand the "hospital" to China's life and the significance of the environment.

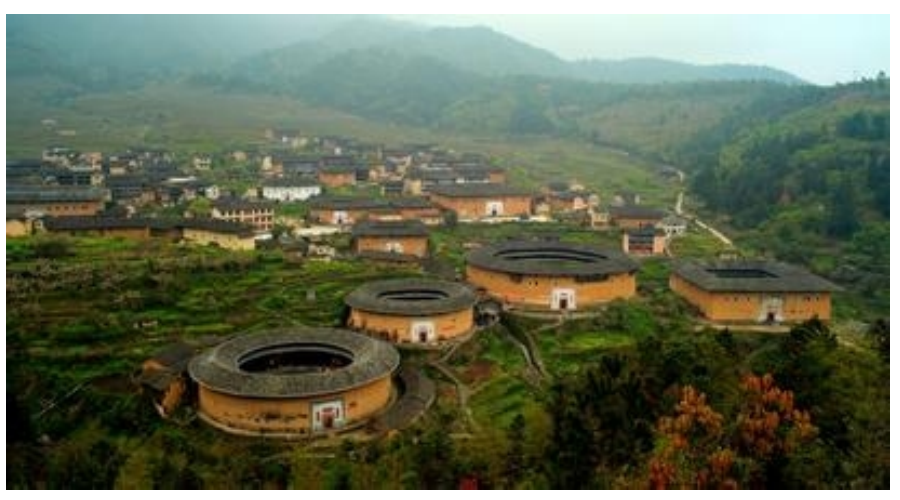

Fig.5

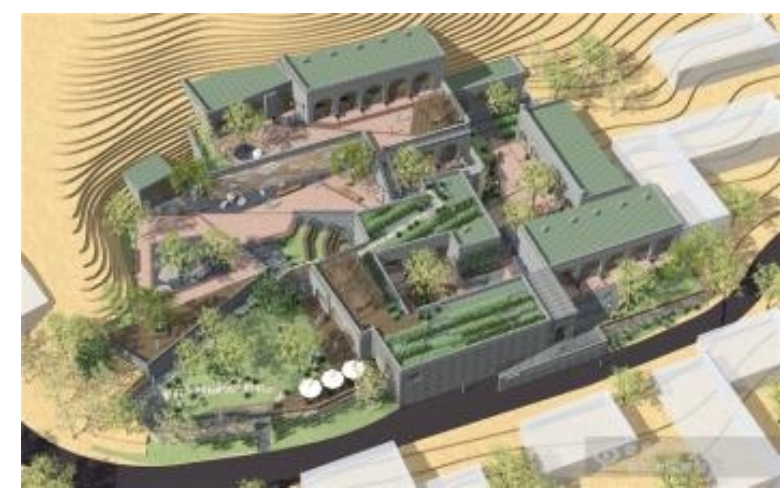

Fig.6

Local residential space, ecological spirit using natural materials, is a kind of form reflects the harmony between man and nature. Because of the natural material of non-toxic properties and processing in a large extent can still reflect the natural characteristics and meet people return to innocence, melting on the nature of the psychological requirements. Such as the cave of Tibetan stone house, northeast of the well dry wooden houses, Yunnan bamboo, northwest, Inner Mongolia tents, they use local materials, to adapt to the local climate, and nature be in harmony is an organic whole. Unique texture and color of natural materials are easy to inspire people's psychological feelings. 
Wood texture like smoke flow and texture cordial warmth; marble or like mountains and valleys, or like the waves of the sea of clouds, give a person with endless reverie.

As mentioned earlier, the traditional houses with distinctive regional features and how the light of local conditions to develop and protect the local characteristics, from the essence of traditional vernacular architecture "shape" and "God" absorb nutrition, the creation has the local characteristics of the modern residential building is a problems worthy of attention.

\section{Inspiration to the design of new rural residence}

Currently domestic construction industry inheritance for the traditional houses are generally first analysis around the local residential characteristics and refining in modern life also has the vitality of traditional elements, in the context of modern life and modern technology, the dialectical view of inheritance and continuity, so that the modernization of traditional architecture. Several commonly used methods are mainly to find local ecological patterns, residential design and semiotics and so on.

i)Analysis of regional differences in natural conditions, looking for local ecological model

Seeking the regional difference of the dwelling in the natural geographical environment. The development of human civilization has accumulated rich experience in residential design, the form of traditional houses in different regions has evolved over thousands of years, and its structure, layout, form its own rationality. Traditional houses always make full use of natural conditions, select the favorable climate, hydrology, geography etc. environment, adjust measures to local conditions, local materials, which contains a prototype of the original ecological thought. Local ecological model technique is from traditional vernacular dwellings, ecological philosophy of using modern technology strengthen the passive energy-saving efforts, build a basic model unit, thus mass used in the majority of residential buildings, the transformation and innovation. The key point of the model lies in the ecological and low energy consumption of the model. Although the shape is new, but its energy use is to follow the original local building energy saving ideas, and the formation of the scale of the final definition of the new regional characteristics. Because the traditional vernacular architecture has always stressed the combination with the natural environment, itself is a kind of simple ecological architecture. Therefore, these ideas will be refined, using new materials, new technology to express, it has formed an unprecedented ecological construction mode. Has a fairly wide range of common sense.

Such as Gansu, Shaanxi and other places in the planning and design of the cave in(Fig.6), it will be updated by the idea of sustainable development into the use of new technologies, explore ancient ecological value technology, make full use of geothermal energy, wind energy and solar energy, the formation of the natural balance of the ecological system of the cave, into a new flavor of modern civilization is ancient cave the new system maintains the advantages of the original ecological cave dwelling, such as saving the land in winter and cool in summer, not destruction of vegetation, fire and wind, debris flow, no noise, no radiation, no air pollution and so on, but also a good solution to the old dark cave, muggy and poor seismic capacity problems, open up the new road in sunlight to the old way of living.

In addition, the new rural residential planning can be reasonably used natural environment and topography. For example, the mountains screen block north to the winter cold; and water can meet the south part of the summer wind, but also has convenient in life and irrigation water; Chaoyang can gain good sunshine; mild slope can avoid flood waterlogging disaster; vegetation can maintain soil microclimate adjustment. Full consideration of the natural factors, in the agriculture, forestry, animal husbandry, animal husbandry, fishing, fishing, and the formation of a virtuous cycle of positive ecological cycle.

ii) From the residential culture to find the characteristics of traditional residential houses, the use of residential "class" design methods

The "class" design of traditional houses is the representation of some refined elements in traditional houses. The space constitution, the form characteristic, the environment consciousness, the place 
spirit and the social adaptation of the traditional dwelling house can be used as the source of the "class" design. Class "design" does not mean to figure thing copying and imitation, the core of class "design" is "class", "class" is "like", paradigm of traditional folk houses in the elements in residential design mode of reproduction is similar in appearance, can be a likeness can also be both God shaped. Elements of the same dwelling in the "class" design patterns of reproduction, can be local, can also be all, can be tangible, can be invisible, or both. Synthesis of new courtyard domestic earlier to explore the traditional residential space put forward four kinds of branch of the new neighborhood system, scattered with the high and low residential, guojielou of closed by Professor Wu Liangyong Tsinghua University presided over the design of "juer Hutong in Beijing" (Fig.7)of the renovation project. Residential first wall by original houses on the old grey brick, makes full use of the original material, the upper is fenqiangdaiwa, embodied in the residential "organic renewal", not only the residents living conditions have improved, but also for the residents provides a good environment for human living. Juer hutong is the traditional courtyard around the courtyard of a single room integration into according to modern living features of unit type residential floors, reversing the households courtyard into multi family "Warren" development trend. After the establishment of the new order around the courtyard space, give the garden space with new vitality.

iii) Refined vocabulary of traditional residential buildings, new residential application of symbol system

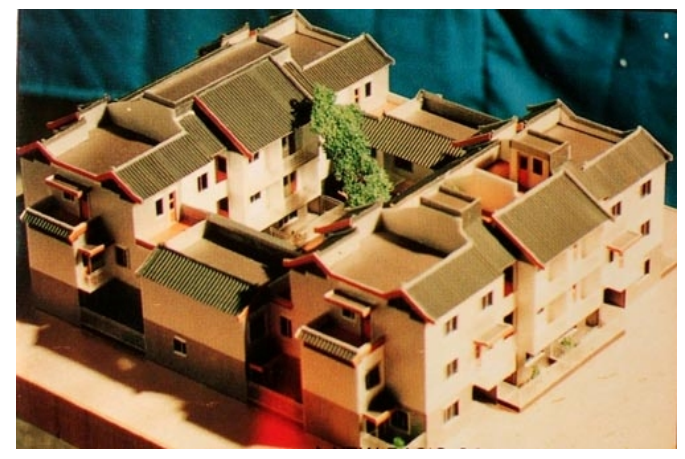

Fig.7

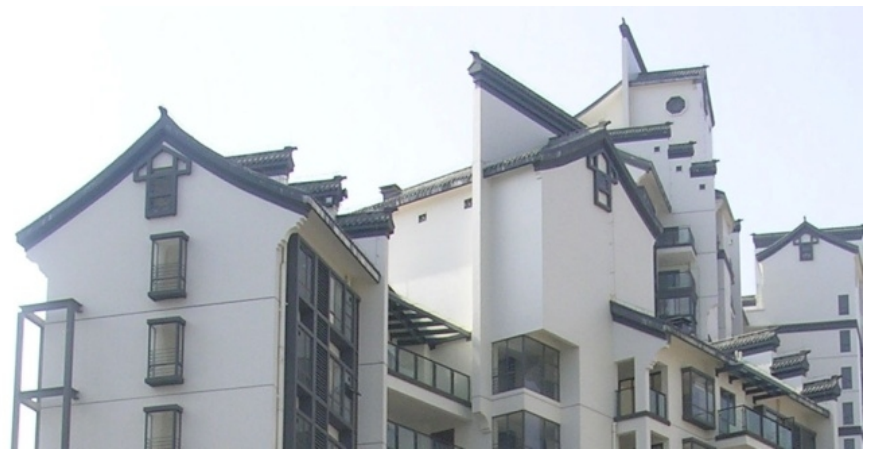

Fig.8

Local folk houses have obvious local characteristics, and their modeling methods are of high artistic value. It is more important to keep the traditional architectural symbols, to increase the architectural area of the region, and to those areas which are still in good condition. Symbol is the exterior of the building, the most likely to affect the visual sense of the part, it can effectively spread the image of information, the performance of the architectural intent has an important role. Symbols to their own image reflects the characteristics of the construction of the building, not only to beautify the building, but also to convey the unique cultural connotation and aesthetic information. Similarly, traditional houses in a variety of exquisite beautiful, very unique components, although the function has the regression, but in the role of people's nostalgia, aesthetic habits, as a symbol of a traditional culture still has a strong vitality. Because of the technology, update, the elements of traditional residential architecture can be used in the original copy, and to in a prototype based, through deformation, dislocation, reversal and refined technique, will the traditional residential component abstraction, geometry, construction of, and then to modern architectural design, resulting in line with modern people's aesthetic orientation of contemporary residential, new residential symbols formed contemporary residential, new residential style(Fig.8), is symbol system application. From the traditional residential colony organization to architectural form of hanging peak, hard mountain, transparent facades, brackets, painting and so on constituent elements, and for various forms of indoor space division cover, Bogut frame, partition board and other elements, the traditional culture symbol or a pattern can be applied to the design of modern residence.

iv) Vigorously develop new rural residential ecological building materials

The construction of new rural residential building should be a green environmental protection building system, and realize the sustainable development of human settlements. The construction 
materials, construction materials also reflects the ecological consciousness of the traditional. Building materials mostly use local materials, on the one hand, these natural materials from local materials, only need simple processing and low transportation cost, so the price is low; simple on the other hand, the construction waste disposal, will not pose a burden and a threat to the environment, some material such as bamboo nog stone can even recycling. The use of local materials to build houses for reducing the consumption of resources and protecting the ecological balance is of great significance.

In addition, we should vigorously develop ecological building materials. At present, China is still in the building materials industry engineering technology is relatively backward in time, materials resource utilization is not high. Therefore, the development of ecological building materials should be energy conservation, resource requirements, improve product quality, reduce energy and resource consumption. Ecological building materials from the material design, production, application, until waste disposal should be in harmony with the environment, both for the purpose of sustainable development. As people deeper understanding of ecological building materials, ecological building materials will be widely applied, so as to ensure that the building materials industry to achieve sustainable development, and the sustainable development of the national economy and the whole society of China's sustainable development and play its due role.

\section{conclusion}

Derived from the above analysis, the function of the rural residential is very complex and complicated, so in the design to fully respect the local customs, respect the rural ecological environment, adjust measures to local conditions, reduce the economic cost and taking into account aesthetic principles. At the same time, in the new rural construction should not be blindly to urban residential learning, should switch direction, from the aspects of materials, layout, detail, structure and technology to the traditional residential study, carry forward the advantages of its environmental protection, energy saving, economy, also make new rural housing without loss of the local ethnic characteristics, design and construction really fit and can improve the rural life of new rural housing.

\section{Acknowledgements}

The research work was supported by the Department of higher education of Guangdong Province outstanding youth teacher training program funded project under Grant No. Yq2013176 and Zhuhai Social Science Association project under Grant No. 2014084.

\section{References}

[1] Liu Yuan.festival and city image design.J.Journal of architecture.07,(2006).35-38.

[2] Yang Min. Space function design and planning of new rural residential building .J. Chinese and foreign architecture,12, (2013). 83-85.

[3] Li Jing. New rural residential design exploration .J. Jiangxi building materials, 04, (2008). 66-68.

[4] Fan Dongying. Research on design strategy of new rural residence .J. Anhui agricultural science, 18, (2010). 112-115.

[5] Wang Ying. The local cultural characteristics of the city street landscape design and research of. Xi'an University Of Architecture And Technology. (2004).108-118.

[6] Tong Zhongjian. Modern city by culture to study the leading .J.culture. 08,(2002).50-51. 